\title{
Impacto de un programa de nivelación de ciencias básicas en estudiantes de primer año de la carrera de Medicina
}

\author{
LUCÍA SANTELICES ${ }^{a}$, CAROLINA WILLIAMS ${ }^{a}$, ALEJANDRO J. ZÁRATE, \\ MAURICIO SOTO ${ }^{b}$, NATALIA JARA S., ALBERTO DOUGNAC
}

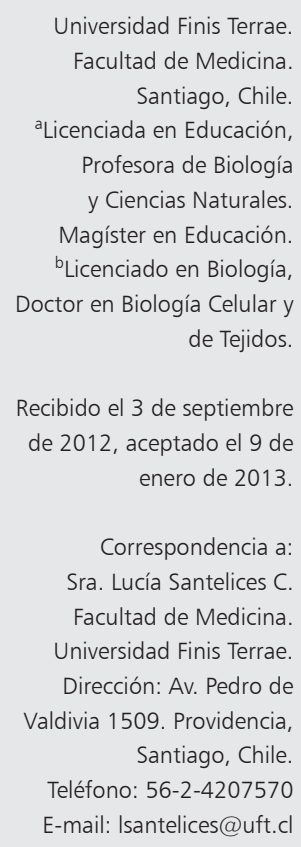

Universidad Finis Terrae. Facultad de Medicina. Santiago, Chile.

aLicenciada en Educación, Profesora de Biología y Ciencias Naturales. Magíster en Educación. bicenciado en Biología, Doctor en Biología Celular y de Tejidos.

Recibido el 3 de septiembre de 2012, aceptado el 9 de enero de 2013.

Correspondencia a: Sra. Lucía Santelices C. Facultad de Medicina. Universidad Finis Terrae. Dirección: Av. Pedro de Valdivia 1509. Providencia, Santiago, Chile. Teléfono: 56-2-4207570 E-mail: Isantelices@uft.cl

\section{Effects on academic performance of a leveling program in basic sciences in first year medical students}

Background: A significant number of students in health careers do not have the knowledge to approve basic courses. Therefore, educational programs to level off knowledge have been developed. Aim: To associate the results of a leveling program with the academic performance in cell biology $(C B)$ and biochemistry $(B C)$ of first year medical students. Material and Methods: We applied a test to first year medical students at the beginning and end of the leveling program (control test). The results obtained at the end of the leveling program were correlated with the results obtained in $C B$ and BC. Results: Fifty seven of 89 (64\%) first year medical students met the study entry criteria (54\% female). Students who completed the leveling program had a significantly higher approval rate in CB (93\% versus $75 \%, P=0.024)$, and in $B C(95 \%$ versus $69 \%, P=0.001)$. After completing the leveling program, the risk of failing $C B$ and $B C$, decreased by 72 and $84 \%$ respectively. Conclusions: This study shows that medical students who participate in the leveling program decrease the chances of failing in $C B$ and $B C$.

(Rev Med Chile 2013; 141: 710-715).

Key words: Cell biology; Biochemistry; Education, medical, undergraduate; Student dropouts.
$\mathrm{D}$ esde antiguo se plantea que educar es hacer realidad el potencial de una persona. Etimológicamente este concepto implica dos acciones; conducir llevando a una persona de un estado a otro y estimular el desarrollo de sus potencialidades ${ }^{1}$. El desarrollo de estas potencialidades implica actualmente para la educación superior y en particular para las escuelas de medicina un desafío, porque significa avanzar desde una concepción de educación restringida, orientada a transmitir conocimientos a una orientada al aprendizaje activo ${ }^{1}$. Este desafío exige al docente evaluar los conocimientos previos de los estudiantes. Un concepto inexistente o mal aprendido, puede entorpecer el aprendizaje futuro ${ }^{2}$. Para considerar estos aprendizajes previos se requiere utilizar instrumentos de evaluación, llamados también pruebas diagnósticas que por una parte evalúan el grado de conocimiento sobre las materias examinadas y por otra determinan la exactitud de los conceptos que las sustentan ${ }^{3}$.

El significativo aumento de estudiantes que ingresan a carreras de la salud ${ }^{4}$ sin poseer los conocimientos científicos suficientes para un buen desempeño en los cursos del ciclo básico ${ }^{5}$, ha generado la necesidad de desarrollar programas educativos de nivelación ${ }^{6}$.

El objetivo de este estudio es asociar los resultados de un programa de nivelación de conocimientos de biología celular (BC) y bioquímica (BQ), 
Programa de nivelación en carrera de Medicina - L. Santelices et al

con el rendimiento académico de estudiantes de primer año de medicina en dichas asignaturas.

\section{Metodología}

Se diseñó un estudio prospectivo, con diseño analítico-descriptivo, enfoque cuantitativo y alcance correlacional. Se desarrolló en la Facultad de Medicina de la Universidad Finis Terrae de la Región Metropolitana de Chile.

El período de estudio fue el año 2010.

En enero de 2010, durante el período de matrícula, a todos los estudiantes de primer año de la carrera de medicina, se les invitó a participar en forma voluntaria al programa de nivelación para algunas asignaturas del primer semestre. Se les indicó la importancia de su asistencia y posible impacto en rendimiento futuro.

Los criterios de inclusión al estudio fueron los siguientes:

Rendición de la prueba diagnóstica de ingreso al programa (test de ingreso).

Asistencia al programa de nivelación.

Rendición de la prueba diagnóstica de control al finalizar el programa (test control).

Para diseñar ambos instrumentos de evaluación se analizaron los contenidos de ciencias básicas involucrados en los programas de asignaturas del primer año de estudio.

Un equipo de profesionales expertos en educación en ciencias biológicas participó en la selección de contenidos de los instrumentos. Esta selección se realizó, mediante comparación entre los contenidos del primer semestre de la carrera, con los programas de biología, química y física de la enseñanza media. A partir de este análisis, se seleccionó un conjunto de conceptos mínimos e indispensables para sustentar los aprendizajes científicos del primer año de la carrera. A estos conceptos se les denominó conceptos científicos claves. De este análisis surgen 9 ejes temáticos, 4 de ellos corresponden al área de biología y 5 al área química (Tabla 1). En función de estos ejes temáticos se diseñó un conjunto de preguntas que dieron forma a un instrumento de evaluación (56 preguntas de selección múltiple; 26 en $\mathrm{BC}$ y 30 en BQ) el cual fue aplicado en forma previa (test de ingreso) y posterior (test control) al programa de nivelación.

Este instrumento fue validado por criterio de jueces, expertos en los dos ámbitos de conocimientos involucrados 5 . Posteriormente, se realizó un análisis de confiabilidad del instrumento (alpha de Cronbach: 0,79). Los resultados obtenidos en el test de ingreso fueron comunicados a cada estudiante de manera personalizada vía correo electrónico antes de su participación en el programa de nivelación.

El programa de nivelación consistió en clases presenciales durante una semana, con un total de 15 h cronológicas. Las clases se realizaron de manera expositiva ajustando sus contenidos a aquellas materias que se detectaron como más débiles en el test de ingreso. Al término de las sesiones presenciales, a cada estudiante se le entregó un disco compacto (CD) que contenía información sobre las materias de los ejes temáticos trabajados durante las sesiones presenciales, para complementar con estudio personal. Este $\mathrm{CD}$ se les entregó teniendo en cuenta que por ser temporada de verano y ser nativos digitales podría facilitarles el repaso de los contenidos en forma independiente. Posteriormente, 5 semanas después de la aplicación del test de ingreso, se les citó para rendir el test de control.

Tabla 1. Ejes temáticos y su número de preguntas asignadas

\begin{tabular}{|lclc|}
\hline Biología & n preguntas & Química & n preguntas \\
Membrana y transporte celular & 6 & Soluciones & 5 \\
Funciones celulares & 6 & Buffer y ácido base & 7 \\
Organelos celulares & 7 & Óxido reducción & 6 \\
Ciclo celular & 7 & Química orgánica & 6 \\
& & Cinética y equilibrio químico & 6 \\
\hline Total & 26 & & 30 \\
\hline
\end{tabular}


Durante el período de nivelación y de estudio independiente, los estudiantes no tuvieron acceso a las preguntas del instrumento aplicado en su forma de post test.

Para comprobar la utilidad del programa de nivelación en el rendimiento académico de los alumnos que accedieron al programa, se realizó un estudio de correlación entre los resultados obtenidas en el test control y los promedios de notas finales obtenidas por los alumnos al término de los cursos de BC y BQ.

El criterio de aprobación para ambas fue el siguiente:

Aprobado: nota igual o superior a 4,0.

Reprobado: nota inferior a 4,0.

\section{Análisis estadístico}

Para el análisis inferencial de los datos se realizaron los análisis de normalidad utilizando las pruebas de Kolmogorov-S-Mirnov, D-Agostino y Shapiro-Wilk a través del programa GraphPad Prism para un $\alpha$ de 0,05 .

Para comparar los resultados logrados por los estudiantes en el test de ingreso y test control se utilizó el test de Student para muestras pareadas.

Para asociar resultados obtenidos en el test de control y el rendimiento académico en asignaturas de BC y BQ del primer semestre se utilizó el test exacto de Fisher junto al test de probabilidad OR (Odds ratio).

Para evaluar el impacto del programa de nivelación sobre el rendimiento académico en las asignaturas del primer semestre se calcularon los riesgos probabilísticos como indicador de magnitud del efecto de la intervención diseñada. En este contexto, se calculó la reducción de riesgo absoluto de reprobar la asignatura (RRA) y la reducción del riesgo relativo de reprobación (RRR) con el fin de expresar la efectividad del programa de nivelación. Se aplicó el cálculo de tamaño de la muestra con la técnica de number needed to treat (NNT) que indica el número de alumnos que se debe tratar o en este caso, nivelar ${ }^{7}$ para reducir en uno, el número de alumnos reprobados.

\section{Resultados}

En el año 2010 un total de 89 estudiantes se incorporaron a la carrera de medicina, de los cuales 57 (64\%) cumplieron con los criterios de ingreso al estudio. Las características de la población es- tudiada se muestran en la Tabla 2. Cien por ciento de estos estudiantes completó las 15 h cronológicas de nivelación presencial. Este grupo ponderó en promedio 679 puntos en las pruebas de selección universitaria (PSU) Lenguaje y Matemáticas, su edad promedio fue de 19,3 años y 54\% eran de sexo femenino. No se registraron diferencias estadísticamente significativas entre poblaciones de alumnos participantes y no participantes del estudio, en términos de sexo, promedio PSU y notas de enseñanza media. Si bien la edad es también similar en ambos grupos, la existencia de un estudiante de 50 años, incrementó la desviación estándar.

El promedio de respuestas correctas en $\mathrm{BC}$ obtenido por los alumnos en el test de ingreso fue de $14 \pm 4$ sobre 26 preguntas $(53 \%)$ y de 9 \pm 4 sobre $30(30 \%)$ para BQ. Ambos valores se incrementan significativamente en el test control para ambas asignaturas: $\mathrm{BC} 21 \pm 2$ sobre $26(81 \%)$; y BQ $13 \pm 4$ sobre 30 (43\%). En BC aumentó el puntaje promedio de respuestas correctas en el test control disminuyendo la dispersión, sin embargo, en BQ mejorando el promedio de puntajes obtenidos se mantuvo la dispersión. El detalle de los datos obtenidos junto a sus respectivos rangos se muestran en la Tabla 3.

Al analizar la predictibilidad de los resultados obtenidos por los alumnos en el test control y compararlos con las notas finales obtenidas en las asignaturas de $\mathrm{BC}$ y $\mathrm{BQ}$, se demostró la existencia de una asociación significativa entre ambas, tanto para BC $(\mathrm{p}=0,0004)$ como para BQ $(\mathrm{p}=0,0001)$. Es decir, a mayor número de respuestas correctas logradas en el test control, mejor nota final en la asignatura correspondiente.

Por otra parte, al analizar el número de alumnos que aprobaron las asignaturas estudiadas, encontramos que los alumnos que participaron en el programa de nivelación, tuvieron una tasa de aprobación significativamente superior a aquellos que no participaron (BC: $\mathrm{p}=0,024 \mathrm{y}$ BQ $\mathrm{p}=0,001)$. Los resultados se detallan en las Tablas 4 y 5 .

De los 19 alumnos reprobados en alguna de las dos asignaturas, 7 asistieron y 12 no asistieron al programa de nivelación. Llama la atención que de los alumnos que asistieron 57\% (4/7) correspondía a mujeres, en tanto de los que no asistieron esta cifra aumentó a $66 \%(8 / 12), \mathrm{p}=1,000$, valor no significativo. 
Programa de nivelación en carrera de Medicina - L. Santelices et al

Tabla 2. Características generales de los alumnos

\begin{tabular}{|lcccc|}
\hline Criterios & $\mathbf{n}$ & Participantes & No participante & Valor p \\
Sexo & Mujeres (\%) & $31(54)$ & $\mathbf{3 2}$ & 0,091 \\
Edad & Media \pm DS & $19,3 \pm 1,76$ & $20 \pm 5,6$ & 0,985 \\
NEM & Media \pm DS & $6,1 \pm 0,3$ & $6,0 \pm 0,3$ & 0,209 \\
PSU & Media \pm DS & $679,3 \pm 27,63$ & $670,8 \pm 26,9$ & 0,099 \\
Ciencias & Media \pm DS & $659,7 \pm 52,45$ & $644,1 \pm 38,6$ & 0,068 \\
\hline
\end{tabular}

Tabla 3. Comparación entre el número y porcentajes de respuesta correctas entre test de ingreso y el test control

\begin{tabular}{|cccccccc|}
\hline Asignatura & $\begin{array}{c}\text { Porcentaje de } \\
\text { respuestas } \\
\text { correctas } \\
\text { Test ingreso }\end{array}$ & $\begin{array}{c}\text { Porcentaje de } \\
\text { respuestas } \\
\text { correctas } \\
\text { Test Control }\end{array}$ & $\begin{array}{c}\text { Rango } \\
\text { (mín/máx) } \\
\text { Test ingreso }\end{array}$ & $\begin{array}{c}\text { Rango } \\
\text { (mín/máx) } \\
\text { Test control }\end{array}$ & $\begin{array}{c}\text { Spearman } \\
\mathbf{r}\end{array}$ & $\begin{array}{c}\text { Intervalo de } \\
\text { confiabilidad } \\
\mathbf{9 5} \%\end{array}$ & Valor $\mathbf{p}$ \\
\hline $\begin{array}{c}\text { Biología } \\
\text { celular }\end{array}$ & $53 \%$ & $81 \%$ & $(4-21)$ & $(16-23)$ & 0,4098 & 0,039 a & 0,027 \\
Bioquímica & $(14 / 26)$ & $(21 / 26)$ & & & 0,681 & 0,007 \\
& $(90 \%$ & $43 \%$ & $(4-16)$ & $(6-21)$ & 0,488 & $0,1374 a$ \\
\hline
\end{tabular}

Tabla 4. Aprobación de la asignatura de biología celular según participación en la nivelación

\begin{tabular}{|lccc|}
\hline & Reprobado & Aprobado & $\begin{array}{c}\text { Valor p } \\
\text { (Fischer) }\end{array}$ \\
\hline Con nivelación & 4 & 53 & 0,024 \\
\hline Sin nivelación & 8 & 24 & \\
\hline
\end{tabular}

OR 0,22 (IC 0,062 a 0,825).

$\mathrm{Al}$ analizar el impacto del programa de nivelación mediante la reducción de riesgo relativo (RRR), encontramos que el riesgo de reprobar en las asignaturas de BC y BQ disminuyó en $72 \%$ y $84 \%$ respectivamente. Por otra parte, el cálculo del number needed to treat es de 5 para BC y 4 BQ. Es decir, se estima que por cada cinco estudiantes que participan del programa de nivelación de $\mathrm{BC}$ y cuatro en el programa de BQ, un estudiante adicional no reprobará la asignatura.

\section{Discusión}

Este estudio evidencia que una proporción considerable de los alumnos de la carrera de me-
Tabla 5. Análisis de la aprobación y el programa de nivelación en la asignatura de bioquímica

\begin{tabular}{|lccc|}
\hline & Reprobado & Aprobado & $\begin{array}{c}\text { Valor } \\
\text { p }\end{array}$ \\
\hline Con nivelación & 3 & 54 & 0,0015 \\
\hline Sin nivelación & 10 & 22 & \\
\hline
\end{tabular}

OR 0,12, IC 0,031 a 0,487.

dicina se beneficia del ingreso a un programa de nivelación en $\mathrm{BC}$ y $\mathrm{BQ}$. Los estudiantes que participan del programa de nivelación disminuyeron las probabilidades de reprobar las asignaturas de biología celular y bioquímica en contraste con aquellos que no participaron del programa.

Los programas de nivelación han demostrado su validez en otras instancias de formación. En carreras de ingeniería se ha publicado que los cursos de nivelación permiten corregir debilidades académicas de los estudiantes y han demostrado su impacto positivo en las calificaciones de primeros años de sus cursos universitarios ${ }^{8}$. En este caso los estudiantes mostraron mayor debilidad en los conceptos claves de bioquímica porque algu- 
nos sólo estudian química hasta segundo año de enseñanza media, y es en tercero y cuarto medio donde tratan temas importantes para los cursos del primer año de la carrera.

La similitud en las tasas de reprobación entre BC y BQ se pueden explicar por la variable profesor que no es materia de este estudio, sin embargo, este impacto ha sido referido en otros estudios?.

Otros estudios han identificado a los programas de nivelación como un medio eficiente para atenuar el impacto negativo de una formación académica deficiente de la enseñanza media sobre el rendimiento alcanzado por los alumnos que ingresan a carreras universitarias ${ }^{10}$.

En Chile, un informe publicado por el centro de microdatos de la Universidad de Chile durante el año 2008, indica que los programas de nivelación o remediales presentan un impacto positivo de $60,6 \%$ en estudiantes que ingresan a universidades privadas ${ }^{11}$.

Este estudio demuestra que la aplicación de un programa de nivelación presenta efectos positivos en estudiantes que ingresan a la carrera de medicina y que poseen puntajes promedios inferiores a los establecidos por las escuelas de medicina tradicionales de nuestro país.

Los estudiantes que participaron en nuestro programa mejoran la adquisición de conocimientos científicos claves para enfrentar el aprendizaje requerido en los cursos de biología celular y bioquímica durante el primer semestre de su carrera. Se observa una asociación directa entre el rendimiento obtenido en el test control y el rendimiento logrado en los cursos mencionados.

El hecho que la participación del programa de nivelación disminuya el número de reprobaciones en los cursos de BC y BQ, es similar al reportado en otros estudios, los cuales dan cuenta del valor de este tipo de programas, para reducir porcentajes de fracaso y abandono entre alumnos recién ingresados a una carrera universitaria exigente ${ }^{7}$.

Lo anterior se podría atribuir a diferencias entre el grupo sometido al programa de nivelación y el grupo que no lo realizó. El análisis realizado permite descartar lo anterior, ya que ambos grupos no difieren significativamente en cuanto a sexo, edad, notas de enseñanza media y PSU.

Para alcanzar estos resultados se requiere que el programa de nivelación se focalice en los conceptos científicos claves de las asignaturas de primer año. Se ha demostrado que el conocimien- to y manejo de estos conceptos claves permiten resolver eficazmente los problemas y situaciones que se presentan en cada una de estas disciplinas ${ }^{12}$.

Para ello es necesario primero detectar y luego enseñar aquellos conceptos que deberían haber sido adquiridos en la enseñanza media para facilitar así el aprendizaje posterior.

Aun cuando el programa de nivelación fue acotado en su fase presencial y con un estudio personal libre, presenta un impacto positivo en el rendimiento académico de los estudiantes universitarios participantes ${ }^{13}$.

El haber comunicado individualmente las debilidades en los conceptos claves detectados en la prueba diagnóstica, podría ser un factor que estimule la motivación de los estudiantes e influya positivamente sobre los resultados obtenidos.

La asociación detectada entre los resultados del test control y el rendimiento académico de los estudiantes que cursaron el programa de nivelación, permite postular que la adquisición de conocimientos científicos claves podría ser un buen predictor en el rendimiento académico en las asignaturas del ciclo básico.

A nuestro juicio, este trabajo presenta algunas limitaciones que sería importante considerar en estudios posteriores:

1. Estudiar la metodología de enseñanza utilizada por los profesores.

2. Cuantificar el tiempo destinado al estudio personal.

3. Diseñar un estudio que permita identificar factores predictores de reprobación en estudiantes que realicen la nivelación.

En resumen nos parece que un programa de nivelación como el planteado es altamente beneficioso ya que reduce significativamente el riesgo de reprobar asignaturas durante el primer semestre de la carrera.

Este estudio sirve como modelo efectivo para instituciones que aceptan estudiantes con puntajes de admisión menores a las instituciones tradicionales en carreras con alto grado de exigencia académica.

\section{Referencias}

1. García Hoz V, Editores. Introducción General a una pedagogía de la persona. Madrid, España. Editorial RIALP. 1993. 
2. Pozo JI. Teorías cognitivas del aprendizaje. Ediciones Morata. Madrid (2010).

3. Cronbach LJ. Test reliability; its meaning and determination. Psychometrika 1947; 12 (1): 1-16.

4. Cruz-Coke R. Evolución de las universidades chilenas 1981-2004. Rev Med Chile 2004; 132: 1543-9.

5. Allgood WP, Risko VJ, Álvarez MC, Fairbanks MM. Factors that influence study. En: RF Flippo y DC Caverly (Coord.), Handbook of college reading and study strategy research, NJ LEA 2000; (pp. 201-19).

6. Brito J, Labra J, Parra E, Editores. Evaluación del aprendizaje y la enseñanza. Santiago, Chile: Ediciones Universidad Católica Silva Henríquez; 2003.

7. Rivera S, Larrondo F, Ortega J. Evaluación de los resultados en un artículo sobre tratamiento. Rev Med Chile 2005; 133: 593-6.

8. Sánchez-Torrubia MG, Castiñeira EG, Jiménez V. Análisis del impacto de un curso de nivelación y apoyo en las calificaciones de los alumnos de primer curso en la Facultad de Informática, Fundación General de la U.P.M. Madrid: España. WSEAS Trans. on Advances in Engineering Education Issue 2006; 3: 984-90.
9. Tejeda Fernández J. El papel del profesor en la innovación educativa. Algunas implicaciones sobre la práctica innovadora. Revista Educar 1995; 19: 19-32.

10. Cu Balán G. El impacto de la escuela de procedencia del nivel medio superior en el desempeño de los alumnos en el nivel universitario. Revista electrónica iberoamericana sobre calidad, eficacia y cambio en educación. Vol. 3, Número 1, especial Red Iberoamericana de Investigación sobre cambio y eficacia escolar. Madrid, España. 2005; pp 764-9.

11. Informe ejecutivo: Estudio sobre causas de la deserción universitaria. Centro de microdatos, Departamento de Economía, Universidad de Chile. (2008). http://archivohistórico.ucv.cl/files/cuentas/cuenta2005_files/cuenta_ de_rectoria/vice_rectoria_de_asuntos_docentes_y_estudiantiles/cuenta_direccion_de_asuntos_estudiantiles. pdf.

12. Vergnaud G. A trama dos campos conceituais na construcao dos conhecimentos. Revista do GEMPA, Porto Alegre, No 4: 9-19 (1996).

13. Kirby JR. Cognitive strategies and educational performance. N.Y: Academic Press 1984. 